\title{
Self-adhesion X-ray Shielding Composite Material of EPDM Rubber with Barite: Mechanical Properties
}

\author{
VASILIY CHERKASOV ${ }^{1}$, YUIY YURKIN ${ }^{2 *}$, VALERIY AVDONIN ${ }^{1}$, DMITRIY SUNTSOV ${ }^{2}$ \\ ${ }^{1}$ OgarevMordoviaStateUniversity, Applied Mechanics Department, 68 Bolshevistskaya Str., 430005, Saransk, Russia \\ ${ }^{2}$ VyatkaStateUniversity, Building Structures and Machines Department, 30 Moskovskaya Str., 610000, Kirov, Russia
}

Abstract. It is actual now to work out new radiation protecting sheeting on the basis of non-curing polymeric composition which possess self-adhesion properties, are easily mounted and dismantled and provide high tightness and low permeability. Mechanical properties of non-curing composites consisting of ethylene propylene diene monomer (EPDM), industrial oil (IO), alkyl phenol-formaldehyde resin (PF) with addition of barite (52\%) to the total material volume were investigated in this article. The aim of investigation is to find optimal content of the above mentioned components at which it would be possible to get the following properties: composite would be sticky enough (peel strength not less than $4 \mathrm{~N} / \mathrm{cm}$ ); character of a separation would be cohesive (on a material) and thus there would be no migration of softener and satisfactory resistance of fluidity. The results showed that PF addition till $20 \%$ in the system EPDM/PF leads to the increasing of adhesive strength, in this case optimal oil concentration in the system EPDM/PF/IO is in the interval from 45 till $55 \%$. New self-adhesion lead-free material, exhibited higher $X$-ray-shielding properties, is also received in the result of investigation.

Keywords: X-ray-shielding, Radiation protection, Mechanical properties, Ethylene propylene diene monomer (EPDM), Barite, Rubber composites

\section{Introduction}

Roentgen rays as diagnostics method in medicine, have declared about its advantage more than 100 years ago. Within time ionising methods of research were improved and became complicated. Except $\mathrm{X}$-radiography, there wasphotoroentgenographyabout 60 years ago, then X-ray computer and positronemissive tomographies [1]. The first three kinds of research use Roentgen rays, the last one uses gammarays. X-ray and gamma-rays are one of the most rigid ionisingradiation. The yielded radiations are characterised by high making through ability. Despite advantage they bring they alsopossess pernicious action on live cages of a human body at long influence or in big doses.

Now some basic ways existto decrease doses of ionising irradiation on patients and medical personnel. First, space-planning actions: distance increase from radiation source to the person. Secondly, organizational actions: time reduction of possible stay of the person in the zone of possible defeat, decrease dosage rate of radiation. Thirdly, constructive actions: creation of filters (boards, walls, partitions, casings) between a source and a person [2,3].

The choice of a filter material depends on a kind of radiation and its energy. X-ray tubes remain the most widespread sources of radiation in medicine. Basically X-ray tubes with energy of photons from 60 to $100-120 \mathrm{keVare}$ used at diagnostics and 150-200 keV at therapy [4,5].

The main complexity of filters application is an enough limited choice of materials for their manufacturing. Screens having composition elements in their content with big charging number of an atomic nucleus are often applied to protectfrom X-rays action. Such elements possess high relative density. Among such elements iron, lead, tungsten [6] are usedmore often. But modern lines of creation of harmless materials demand to refuse from lead because of its high toxicity $[7,8]$.

Tungsten is the metal possessing big charging number of an atomic nucleus, causes interest among many researchers. In works $[9,10]$ results of researches of effective work of a composite complex

\footnotetext{
*email: yurkin@vyatsu.ru
} 
polymer-tungsten in ionising radiation decrease are presented. In the work of H. M. Soylu with coauthors [11] test results of the composition on the basis ofethylene-vinyl acetate, filled with tungsten carbide are presented. On the basis of work it is possible to make a conclusion that metal-polymeric composition possesses the best radiation shielding properties at degree of filling of $70 \%$.

Adding metal powders as fillers increases radiation shielding properties of a composite material. But with growth of a metal filler part in the polymeric material, the last can get a few not characteristic for it before properties: electric conductivity, magnetic susceptibility, etc. [12] As at a partgrowth of a heavy filler decrease of some physical-mechanical properties is observed: strengthening and the adhesive properties fall.

Application of metals as materials toprotectfromionising radiation is considered to be a traditional method of protection. The barytic plaster can be appliedas one of traditional method of protection. So the barytic plaster FullMIXroentgen shielding has received wide popularity as a radiation shielding material. Disadvantage of use of the yielded material for protection is wet technological process of its moulding, and also complexity of its dismantle after its saturation by radio nuclides.

Barium sulphate (BaSO4) is a very popular filler of radiation shielding materials [13-15]. This material is pollution-free and does not display toxic properties. In work of Seon-Chil Kim with coauthors [16] results of researches on creation of radiation shielding screen used in medical institutions are presented. In the described material synthetic rubber and silicone blend was applied as aknitting core. Barium was chosen as the basic filler into which tungsten and tourmaline were added as improving additives. So it was stated, that barium application allows to receive effective highly filled radiation shielding material. However this material has some disadvantages affecting operational properties. First, the material made in the form of a sheet, possessed bad flexibility. Second,stickiness to some surfaces was absent. Besides technological disadvantages - complexity of blend manufacturingbecause of high density and big maintenance of barium in the blendwere also revealed.

All materials listed above, despite enough high indexes of easing of ionising radiation, have a few essential disadvantages: limitation of form-building, low flexibility. Often special keeping devices which do not allow to create tight joints through which radiation infiltration is possible are applied for installation of such materials.

In work [17] methods to increase adhesive properties of a radiation shielding material with barytic filler by addingvarious quantity of alkyl phenol-formaldehyde resininto the composition are described. Authors come to opinion, that optimum quantity of resin in polymer is $6 \%$ in volume.

The practice showed thatbarite was better thanother materials for creation of material for radiation shielding screens. It possesses necessary absorption capacity of ionising radiation with energies from 60 to $100 \mathrm{keV}$, low price and availability.

On the basis of the presented results it is possible to make a conclusion about creation possibility of self-adhesive radiation shielding material on the basis of synthetic rubber with physical-mechanical properties determined earlier. The main task at creation of such material is definition of a filler part at which the composite would possess sufficient density, but would remain sticky enough (peelstrength not less than $4 \mathrm{~N} / \mathrm{cm}$ ); character of breakoff would be cohesive (on a material), resistance to tearing up more than $0,2 \mathrm{MPa}$ and factor of linear easing for X-rays not less than $6 \mathrm{~cm}^{-1}$ and thus there was no migration of plasticizer and satisfactory resistance of fluidity.

\section{Materials and methods}

\subsection{Materials}

Radiation shielding material represents uniform mixture of basis-rubber, plasticizer, filler and improving additives.EPDM 50 (Ufaorgcintez, Russia) is used as the basis for polymeric composite. Choice of EPDM as the binding is connected with that that rubber, and as other materials on its basis have flexibility and stickiness, which are necessary to create self-adhesive radiation shielding material.Plasticizerisindustrialoill-40 State Standard 20799-880 (RussNeft, Russia). MicrobariteMibari 
(GeoKOM, Russia) is used as a filler. Alkyl phenol-formaldehyde resin SP-1045 ("SI Group", France) is used as agent of stickiness.In spite of all positive qualities alkyl phenol-formaldehyde resin is only as an improving additive in the material. It is caused by the fact that it is extremely problematic to create flexible radiation shielding material, where only resin is binding.

Compositions and brands of the studied composites are given in Table 1.

Table 1.Compositions and brands of the studied composites

\begin{tabular}{|c|c|c|c|c|c|c|c|c|}
\hline & \multicolumn{3}{|c|}{ Vilume fraction, \% } & \multicolumn{5}{c|}{ Mass fraction, g } \\
\hline & EPDM 50 & I-40 & Mibari & SP-1045 & $\begin{array}{c}\text { EPDM } \\
50\end{array}$ & I-40 & Mibari & SP-1045 \\
\hline ES0-I50-B52 & 24 & 24 & 52 & 0 & 9.19 & 7.78 & 92.56 & 0 \\
\hline ES0-I55-B52 & 21.6 & 26.4 & 52 & 0 & 8.35 & 8.64 & 92.56 & 0 \\
\hline ES0-I60-B52 & 19.2 & 28.8 & 52 & 0 & 7.51 & 9.50 & 92.56 & 0 \\
\hline ES0-I65-B52 & 16.8 & 31.2 & 52 & 0 & 5.85 & 11.23 & 92.56 & 0 \\
\hline ES10-I45-B52 & 23.76 & 21.6 & 52 & 2.64 & 8.27 & 7.78 & 92.56 & 1.48 \\
\hline ES10-I50-B52 & 21.6 & 24 & 52 & 2.4 & 7.51 & 8.64 & 92.56 & 1.34 \\
\hline ES10-I55-B52 & 19.4 & 26.4 & 52 & 2.16 & 6.76 & 9.50 & 92.56 & 1.21 \\
\hline ES10-I60-B52 & 17.28 & 28.8 & 52 & 1.92 & 6.01 & 10.37 & 92.56 & 1.08 \\
\hline ES10-I65-B52 & 15.12 & 31.2 & 52 & 1.68 & 5.26 & 11.23 & 92.56 & 0.94 \\
\hline ES20-I45-B52 & 21.12 & 21.6 & 52 & 5.28 & 7.35 & 7.78 & 92.56 & 2.96 \\
\hline ES20-I50-B52 & 19.2 & 24 & 52 & 4.8 & 6.68 & 8.64 & 92.56 & 2.69 \\
\hline ES20-I55-B52 & 17.28 & 26.4 & 52 & 4.32 & 6.01 & 9.50 & 92.56 & 2.42 \\
\hline ES20-I60-B52 & 15.36 & 28.8 & 52 & 3.84 & 5.35 & 10.37 & 92.56 & 2.15 \\
\hline ES20-I65-B52 & 13.44 & 31.2 & 52 & 3.36 & 4.68 & 11.23 & 92.56 & 1.88 \\
\hline ES30-I45-B52 & 18.48 & 21.6 & 52 & 7.92 & 6.43 & 7.78 & 92.56 & 4.44 \\
\hline ES30-I50-B52 & 16.8 & 24 & 52 & 7.2 & 5.85 & 8.64 & 92.56 & 4.03 \\
\hline ES30-I55-B52 & 15.12 & 26.4 & 52 & 6.48 & 5.26 & 9.50 & 92.56 & 3.63 \\
\hline ES30-I60-B52 & 13.44 & 28.8 & 52 & 5.76 & 4.68 & 10.37 & 92.56 & 3.23 \\
\hline ES30-I65-B52 & 11.76 & 31.2 & 52 & 5.04 & 4.09 & 11.23 & 92.56 & 2.82 \\
\hline
\end{tabular}

In the blends, which names contain index I45 a plasticizer part in the basic composition (the system polymeric matrix+plasticizer) is 0,45; EI50 - 0.50; EI55 - 0.55, EI60-0.60, EI65-0,65.

Index ES0 means, that part SP-1045 in a polymeric matrix (EPDM+SP-1045) is 0; ES10 - 0.1; ES20 - 0.2; ES30 - 0.3.

Density of ingredients was applied to recalculate volumeparts in the mass ones, making for EPDM

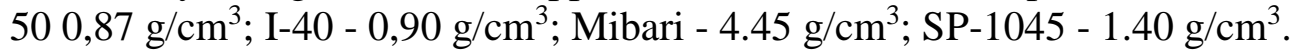

Composite mixtures were made with the help of a batch laboratory mixer with tangential rotors. The polymer was initially stirred at a temperature of $120^{\circ} \mathrm{C}$ at a speed of $44 \mathrm{rpm}$ for $20 \mathrm{~min}$. Further, the polymer was mixed with a plasticizer, then filler and modifier were addedand also continued mixing another 100 minutes. Then from the blend, to determine the homogeneity, not stopping the mixing, every 20 minutes the material sample was selected, and by means of laboratory microscope ZEISS Primo Star supervision of a particle size of barite in the composite was made. At achievement of barite particles of the size of $0.01 \mathrm{~mm}$ displacement was stopped then it was rolled on a rolling mill machine till a material had a uniform thickness.

\subsection{Methods}

Adhesion strength with metal is determined by State Standard 24025. Peel strength with metal is determined by State Standard 21981.Definition of peel strength with metal is manufactured in the tearing machine (Figure 1). Densities, penetration, resistance of fluidity and plasticizer migration are determined by State Standard 25945. 


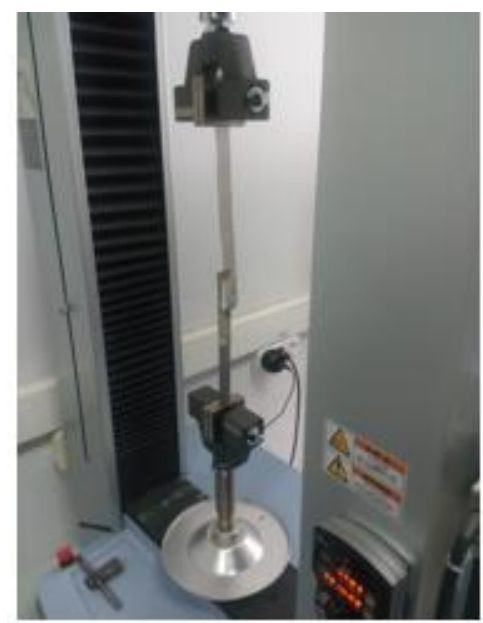

Figure 1. Material test for peel strength from metal

The homogeneity test is carried out by State Standard 25945. The number of test samples must be at least three, one sample taken from each batch.

Each cut surface of the test material is examined using a ZEISS Primo Star microscope, the inclusions are counted and measured. The size of inclusions in each slice of one sample should not exceed 0.01 $\mathrm{mm}$.

\section{Results and discussions}

\subsection{Plasticizer influence on adhesion strength and peel strength to metal}

EPDM has low stickiness and for support of adhesion to metal it is necessary to plasticize it. As it has been found out earlier [22], addition of industrial oil as plasticizer to volume content of $40 \%$ increases adhesion strength, and then it starts to drop. Filled compositions with oil content in the system polymeric matrix+plasticizer $45-50 \%$ vol. show the highest values of peel strength to metal (Figure 2) andadhesion strength (Figure 3).

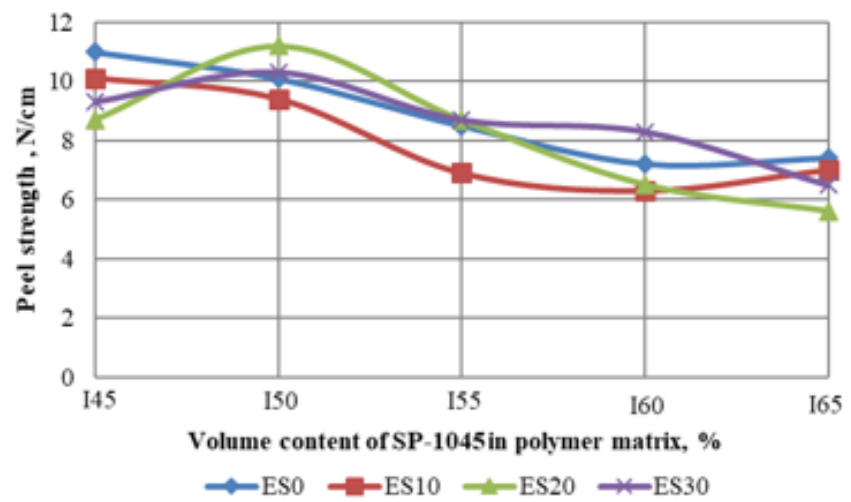

Figure 2. Peel strength from metal at different volume content of oil in polymer blend, \%

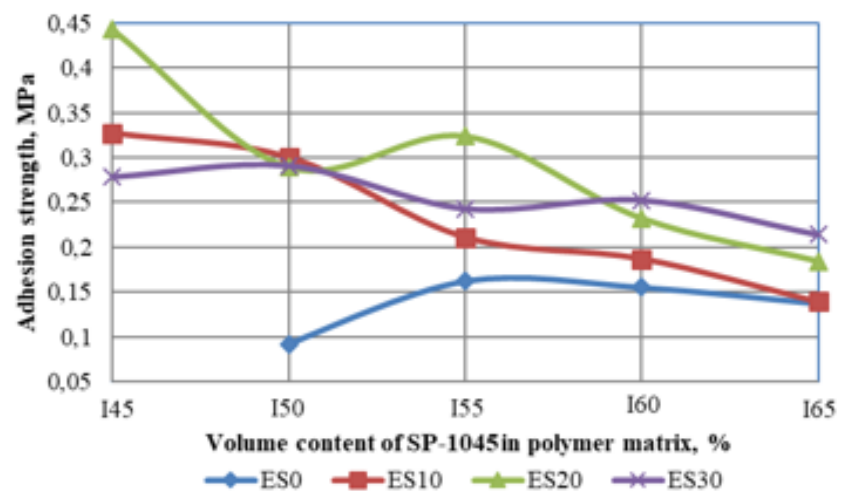

Figure 3. Adhesion strength at different volume content of oil in polymer blend, \% 
3.2. Influence of alkyl phenol-formaldehyde resin on adhesion strength and peel strength to metal

Various sources give researches about increase of adhesion hardness of composites with additionof various resins in their composition.Alkyl phenol-formaldehyde resin can be the most suitable agent of stickiness for composites on the basis of synthetic rubbers [19]. In theyielded article after resin addition research of the received composition is made. Thus resin addition occurs according to high density of filler and volume of resin in the total composition. In this article resin till content of $0,10,20,30 \%$ from system rubber+Sp-1045 was consistently added in compositions with filler content of $52 \%$ vol. and plasticizer contentof 45, 50, 55, 60, 65\%. In volume parts it will make accordingly 3, 6 and $9 \%$. Results of dependence of adhesion strength and peel strength to metal from quantity of resin are shown on (Figure 4, Figure 5). So the increase ofresin partleads to growth of adhesion strength at compositions with plasticizer contentof 45 and $55 \%$. Composition with plasticizer content of $50 \%$ has hardness growth tillresin part of $10 \%$. There is a hardness falling further. Compositions with highcontent of plasticizer more than $60 \%$ show practically growth linear relation of adhesion strength from quantity of resin in the composition. Further increase ofresin part for these compositions is not expedientbecause at growing of resin part there will be a composition glass transition temperature, stickiness will decrease, and hardness will fall. It is necessary to notice that fact, that compositions with resin content less than $10 \%$ showed adhesive character of breakoff.

SP-1045 content in a polymeric composition has weak impact on peel strength from metal (Figure $5)$.

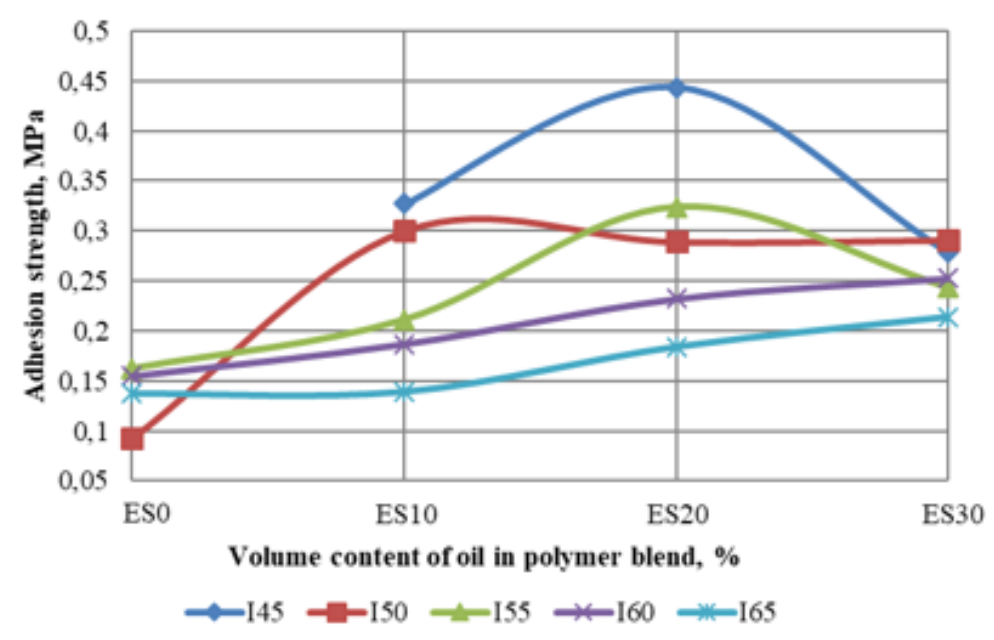

Figure 4. Adhesion strength at different volume content of SP-1045 in polymer matrix, \%

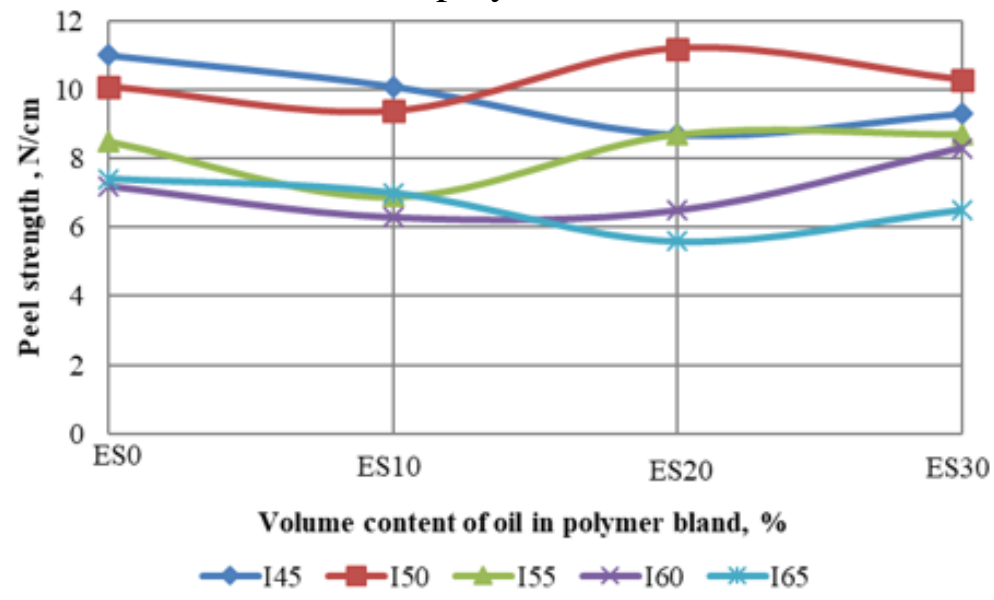

Figure 5. Peel strength from metal at different volume content at different content of SP-1045 in polymer matrix, \% 


\subsection{Influence of plasticizer on penetration and composition density}

Increasingofplasticizer partleads to decreasing of adhesionstrength and peelstrengthtometal.

Besides, inspite of SP-1046 quantity in the composition, amplifying of plasticizer content increases penetration (Figure 6) and slightly reduces composite density (Figure 7).

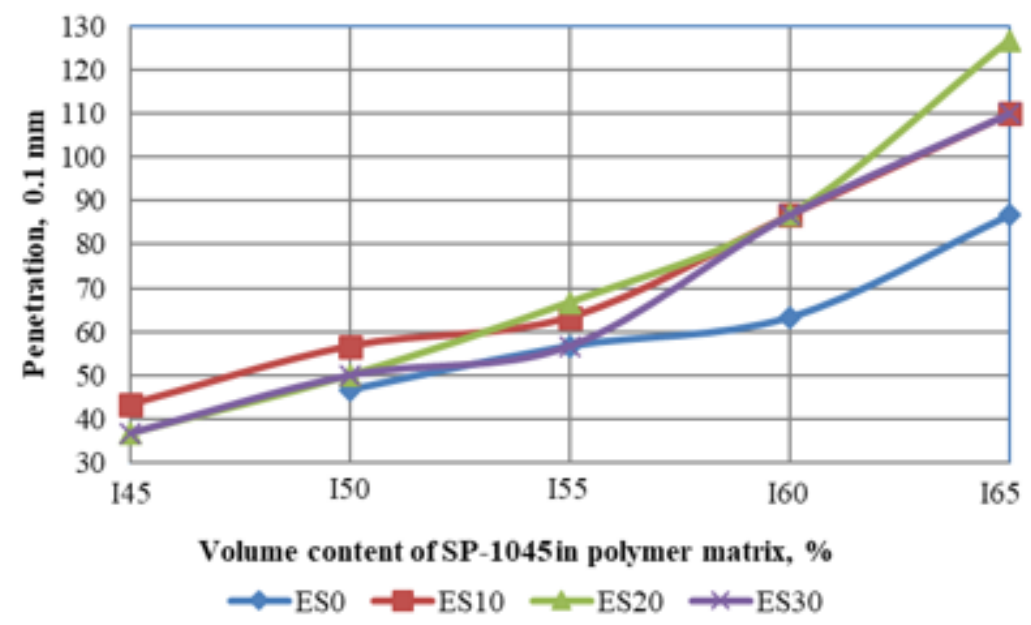

Figure 6. Penetration at different volume content of oil in polymer blend, $\%$

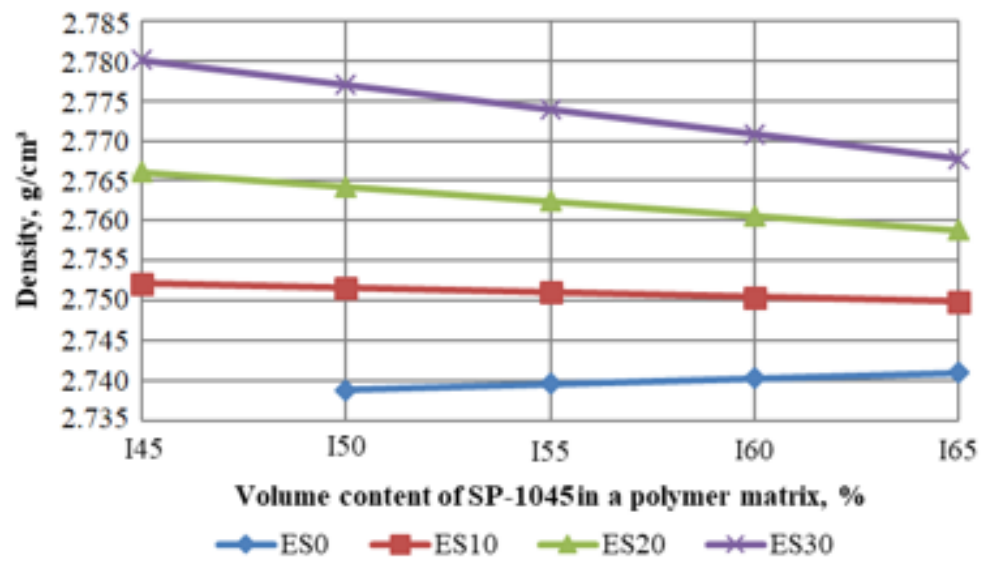

Figure 7. Density at different volume content of oil in polymer matrix, $\%$

Insignificant growth of composition density without SP-1046 content is connected with increase of plasticizer in the composition, which density is higher than rubber density, $0.90 \mathrm{~g} / \mathrm{cm}^{3}$ and $0.87 \mathrm{~g} / \mathrm{cm}^{3}$ accordingly.

At the minimum plasticizer part $45 \%$ vol. composite density is about $2.8 \mathrm{~g} / \mathrm{cm}^{3}$ and penetration is about $3.1 \mathrm{~mm}$, and the difference of these values depending on the plasticizer content is insignificant.

All samples were tested on fluidity resistance, however samples with plasticizer in a polymeric blend $50 \%$ vol. had migration of plasticizer.

\subsection{A linear attenuation coefficient of a material}

All samples of materials wereirradiated to define a linear attenuation coefficient. Fundamental schema of installation for irradiance definition on the laboratory sample is specified on figure 8 . 


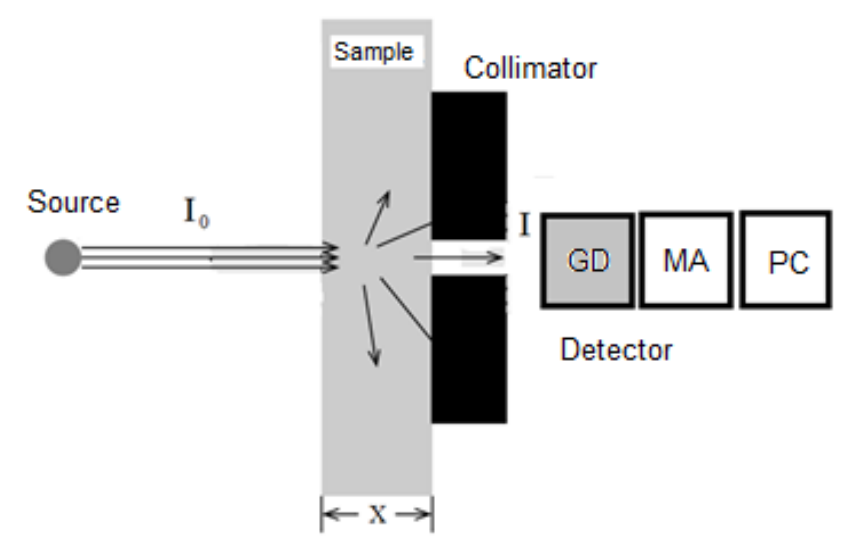

GD - a germanium detector; MA - multichannel analyze; PC - personal computer

Figure 8. Scheme of laboratory equipment

For the test samples of the necessary sizes (100x100) $\mathrm{mm}$ are cut down from a material strip, with thickness measured in advance.

Isotope source of gamma quanta Am-is applied as radiation sources, its energy corresponds to radiant energy of X-ray tube with voltage on the anode $100 \mathrm{kV}$. At carrying out tests with the sample irradiated by source Am-241 the distance from a source to detector end should be $8 \mathrm{~mm}$.

The scheme of samples arrangement at testing is resulted on Figure 9.

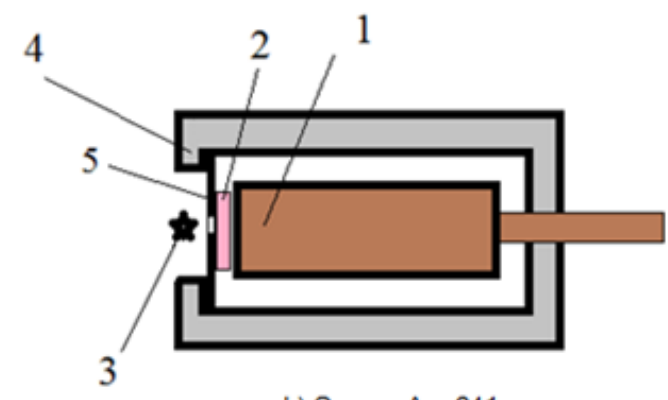

b) Source Am-241

1 - detector of gamma quanta; 2 - sample; 3 - source of gamma quanta; 4 - lead protection; 5 - collimator.

Figure 9. Scheme of sample arrangement at testing

For a source the initial stream of gamma quanta and optimum distance from the end of the detector to a source has been defined. Then in front of the detector end the sample and source of gamma quanta takes places. Thus the detector should be surrounded by lead protection which is a primary collimator in diameter of $5 \mathrm{~mm}$ and protects from background sources of gamma quanta and X-rays. At measurements using Am-241 as a collimator the lead plate with thickness of $0.5 \mathrm{~mm}$ with a collimator in diameter of 5 $\mathrm{mm}$ is applied. After that the stream of gamma quanta which have passed through the sample is measured.

The linear attenuation coefficient of a material (3) in $\mathrm{cm}^{-1}$ is defined under the formula:

$$
\mu=\frac{1}{x} \ln \frac{I_{0}}{I}
$$


where $\mathrm{x}$ - sample thickness, $I_{0^{-}}$initial intensity of an electromagnetic radiation; $I$ - intensity of the incidenting electromagnetic radiation which has passed through a plate from a radiation shielding material.

As followed from a theoretical substantiation, protective properties of a material are in dependence from a filler level, its atomic weight and order numbers in the periodic table of chemical elements. The linear attenuation coefficient for the yielded materials at sample thickness of $5 \mathrm{~mm}$ is in limits of 10,06 $\mathrm{cm}^{-1}$ at voltage on the anode of $100 \mathrm{kV}$. At investigatedsample thickness and radiant energy the lead equivalent for investigated materials was $4 \mathrm{~cm}$. It means, that $4 \mathrm{~cm}$ of the yielded samples provide the same protection, as well as $1 \mathrm{~cm}$ of pure lead at the yielded radiant energy.

Thus, the idea that the filler level in the composite mainly influences its protective properties is again confirmed. It is alsostated, that all from considered materials have factor of linear absorption above 6 $\mathrm{cm}^{-1}$.

\section{Conclusions}

Properties of composites consisting of various percentage ratios SKEPT-Oil-barite are investigated. The area of compositions which meet the requirements of self-adhesive composite is revealed: pull strength from metal not lower than $4 \mathrm{~N} / \mathrm{cm}$, pull strength from concrete not less than $0,2 \mathrm{MPa}$, cohesive character of breakoff, absence of plasticizer migration, satisfactory fluidity resistance, linear attenuation coefficient. It is shown, that composition with maximum barite content meeting these requirements, will be the following: a ratio EPDM/oil in the polymeric blend 55/45, volume barite content $-52 \%$. The resin content in the polymeric matrix is about $20 \%$. The volume resin part in the composite material is about $5 \%$ vol. The yielded composition has density $2.73 \mathrm{~g} / \mathrm{cm}^{3}$. While being tested it showed cohesive character of breakoff and hardness of $8.7 \mathrm{~N} / \mathrm{cm}$, linear attenuation coefficient of $10.06 \mathrm{~cm}^{-1}$. Lead equivalent for the yielded material at voltage on the anode of $100 \mathrm{kV}$ is $4 \mathrm{~cm}$, that twice more than the most widespread method of protection from X-rays influence has - barite plaster which has the lead equivalent of $11 \mathrm{~cm}$. Thus plaster has some disadvantages about which it was mentioned in the introduction.

On the basis of the conducted investigation it is possible to make a conclusion that the yielded composition (ES20-I45-B52) can be applied to manufactureself-adhesive material for protection from radiation in offices ofradiation therapy and diagnostics.

Acknowledgements: The research is executed with financial support of Ministry of Education and Science of Russia. The title of project is "Applied scientific research, oriented to create removable elastic self-adhesive radiation protective coatings that ensure safe handling of radiation-active waste" (code of application form "2018-14-000-0001-028”). Unique identifier of project is RFMEFI57418X0187.

This article was presented at Polymer Processing in Engineering Conference - PPE 2019, 7- 9 October 2019, Galati - Romania.

\section{References}

1. SOWA P, RUTKOWSKA-TALIPSKA J, SULKOWSKA U, RUTKOWSKI K, RUTKOWSKI R., Polish Ann Med [Internet], 19, 2, 2012, p 134-8. Available from: http:// dx.doi. org/10. 1016/j. poamed.2012.07.00

2. BRUDECKI K, KOWALSKA A, ZAGRODZKI P, SZCZODRY A, MROZ T, JANOWSKI P, et al., Radiat Environ Biophys. 56, 1, 2017, p 19-26.

3. Mashkovich V P 1995 Protection against ionising radiation (Moscow: Enerogoatomizdat) p 107 4. *** State Standart МЭК 62220-1-3-2013 Medical electrical equipment. Characteristics of digital Xray imaging devices. Part 1-3. Determination of the detective quantum efficiency/the Electronic text of the document prepared by joint-stock company "Code" and verified on: official publication M: Standartinform, 2015

5. ADELI R, SHIRMARDI SP, AMIRI J, SINGH VP, MEDHAT ME., J ParamedSci Autumn, 6, 4, 
2015, p 2008-4978.

6. ***Jaeger T 1965 Principles of radiation protection engineering (New York: McGraw-Hill)

7. LANSDOWN R, YULE W 1986 Lead toxicity: History and environmental impact (Baltimore: Johns Hopkins University Press)

8. YUE K, LUO W, DONG X, WANG C, WU G, JIANG M, ZHA Y, Radiat Prot Dosim, 2009, 4, p 256260

9. ***Eder H (2006) US Patent Application Publication No. US 2006/0151750 A1

10. McAlister D R 2012 Gamma ray attenuation properties of common shielding materials (USA: University Lane Lisle)

11.SOYLU H M, LAMBRECHT F YURT, ERSO O A, J Radioanal Nucl Chem, 2015, DOI 10.1007/s10967-015-4051-3

12. KATZ G S, MILEVSKI D V 1981 Fillers for polymeric composite materials (Moscow: Chemistry) p 736

13. AKKURT I, BASYIGIT C, KILINCARSLAN S, MAVI B, Prog. Nucl. Energy, 2005, 46, p 111

14. AKKURT I, AKYILDIRIM H, MAVI B, KILINCARSLAN S, BASYIGIT C, Ann. Nucl. Energy, 2010, 37, p 910914

15. SALAH N, HABIB S S, KHAN Z H, AL-HAMEDI S, LOCHAB S P, J. Lumin, 2009, 129, p 192 196

16. KIM S C, DONG K R, CHUNG W K, Annals of Nuclear Energy, 2012, 47, p 15

17.CHERKASOV D.V. Influence of filler content on adhesive properties of radiation-protective sheeting / Cherkasov D.V., Avdonin V.V., Suntsov D. L.//IOP Conference Series: Materials Science and Engineering: IOP Publishing, Chelyabinsk, Russian Federation - 2018. - № 451 - pp. 1-7 - ISSN 17578981 doi:10.1088/1757-899X/451/1/012205

Manuscript received: 24.02 .2020 